\title{
USEFULNESS OF OUT-OF-SCHOOL LEARNING IN SCIENCE EDUCATION
}

\author{
Ryszard M. Janiuk \\ Maria Curie-Skłodowska University, Poland
}

Out-of-school learning has been playing an increasingly important role in science education. It can be implemented in various ways and encompasses learning activities that take place outside normal lessons reserved for compulsory education. This form of education is typically not coordinated by the school itself and young people take part in it voluntarily. It resembles "outdoor education", which is, however, more closely linked with meeting aims stemming from formal education. Since the learning activities used in both forms of education are similar, very often solutions and experiences in one form are transferred to the other.

Educators from many countries have shown considerable interest in out-of-school learning for many years. It is recommended in official documents concerning formal education and by organisations dealing with science education. Already in 1996, the National Science Education Standards, which are a set of guidelines for science education in primary and secondary schools in the United States, emphasised the importance of this method of expanding and supplementing students' knowledge. Similarly, the materials for teachers accessible on the website of the Association for Science Education in the UK contain several useful tips concerning the use of out-of-school learning in science education.

Several factors have had an impact on the development of out-of-school learning. As education is becoming more widely accessible, being currently available to virtually all young people up to the age of 16 in developed countries, and as the financial situation of the education sector is deteriorating, it is becoming more and more difficult to ensure a proper level of instruction in science subjects, particularly if the diverse aspirations and capabilities of individual students are to be taken into consideration. At the same time, increasingly demanding requirements are imposed on science educators; not only is science important in our everyday lives, but it is also necessary to educate experts who will continue to expand our knowledge in this field and help improve the quality of our lives. As our knowledge in science is increasing rapidly, it is difficult to make the necessary modifications in curricula, not to mention introducing entirely new content. Another major issue is the fact that students from several countries have been found to show low interest in science subjects. These findings have given rise to a wide range of initiatives whose aim is to stimulate and develop students' interest in the field. These initiatives have been undertaken by institutions of higher education, which would like to attract a higher number of well-prepared candidates, as well as by industries and businesses interested in hiring staff with an adequate education. It has also been realised that students should be able to spend their time in a productive way outside school. Since out-of-school learning is a good opportunity to do so, it is also much appreciated and encouraged by parents, who are aware of the fact that it can help their children get the best education possible.

There are many different forms of out-of-school learning. One of the oldest and most popular forms is organising regular events, such as science festivals and picnics, whose goal is not just to spread knowledge, but most of all to stimulate and develop students' interest in science. The first science festival was held in 1989 in the capital of Scotland and was called the Edinburgh International Science Festival. One of the fastest developing forms of out-of-school learning is children's universities. The first universities for children were launched in Tübingen, Germany in 2002 and in Vienna, Austria in 2003. Science centres and museums have also played a major role. At present, there are 2,400 science centres operating worldwide and new ones are still being opened. Compared to traditional science museums, science centres emphasise a hands-on approach, and feature interactive exhibits that encourage visitors to experiment and explore. As has already been mentioned, universities, which are interested in 
attracting well-educated candidates, have also participated in organising out-of-school learning. They regularly hold classes designed specifically for students interested in a particular topic, in the form of lectures, laboratories and even research projects. Moreover, every year universities organise open-day events, where knowledge in science is presented to students in an attractive way, in addition to informing them about the education opportunities that a particular university has to offer. Similar events include nights of research, which give students an opportunity not only to gain information and knowledge, but also to meet researchers in a special, informal atmosphere. As far as industries and businesses are concerned, they support out-of-school learning either indirectly by financing the activity of other entities, or directly by making it possible for students to visit laboratories or specially designed exhibitions which present the history of a particular company and give some basic information about its activity. Finally, one has to mention that the media have had a major impact on this form of education. Popular science books, newspapers and magazines as well as radio and television programmes have traditionally been rich sources of information about science and have hosted debates on topical, relevant and often controversial issues. More and more of them use information technology, which encourages active learning, and the Internet, which gives users access to enormous amounts of information.

There are several organisations in the world whose goal is to develop and support out-of-school learning. European institutions which are particularly worth mentioning are the EUSEA (the European Science Events Association) and Ecsite (the European Network of Science Centres and Museums). The first one is a platform for exchanging experiences in organising different forms of science engagement activities such as festivals, summers, weeks, days or nights of research. The second one is a European network of science centres and museums, linking science communication professionals in more than 400 institutions in 50 countries, which connects member institutions through projects and activities, and facilitates the exchange of ideas and best practice on current issues.

One of the many advantages of out-of-school learning is the fact that is helps increase students' interest in education by creating extra learning opportunities in the real world. It also makes it possible to discover gifted pupils and develop their talents. However, there is a major issue that needs to be investigated, which is how out-of-school learning influence students' future actions and decisions concerning science education, bearing in mind that this form of education cannot replace formal education and can only support it. That is why scholars are conducting research with the aim of determining the impact of out-of-school activities on improving the learning of science, especially on outcomes such as achievement, interest in science, careers in science, self-efficacy, perseverance, and effort in learning science (Tran, 2011).

\section{References}

The European Network of Science Centres and Museums, Ecsite (2013). Retrieved March 24, 2013, from http://www. ecsite.eu/about

Eusea (European Science Events Association) (2013). Retrieved March 24, 2013, from http://www.euscea.org/www. euscea.org/AboutEUSCEA/about_euscea.html.

Tran, N. A. (2011). The Relationship between Students' Connections to Out-of-School Experiences and Factors Associated with Science Learning. International Journal of Science Education, 33, 1625-1651.

Ryszard M. Janiuk

PhD., Professor, Head of Department of Chemical Education, Maria

Curie-Skłodowska University, pl. Marii Curie-Sklodowskiej 5, 20-031

Lublin, Poland.

E-mail: rmjaniuk@poczta.umcs.lublin.pl

Website: http://www.umcs.lublin.pl/articles.php?aid=4380 